\title{
FOREIGN LANGUAGE ANXIETY IN UNIVERSITY LEARNING: SELF-PERCEPTIONS OF STUDENTS ENGAGED IN SPORTS
}

\author{
Asta Lileikiené $\dot{e}^{1}$, Lina Danilevičiené ${ }^{2}$ \\ Lithuanian Sports University ${ }^{1}$, Kaunas, Lithuania \\ Lithuanian University of Health Sciences ${ }^{2}$, Kaunas, Lithuania
}

\begin{abstract}
Background. Research aimed at the analysis of self-perceptions of students of foreign language anxiety in the classroom context in relation to its effect on foreign language acquisition. It focused on foreign language, as a skill needed for versatile education, which would lead to a successful career in sports or would aid in pursuing health enhancing leisure activities later in life.

Methods. The qualitative approach of research was adopted in this study. Twenty subjects involved in the study programs as Sports Coaching at the Lithuanian Sports University and Medicine at the University of Health Sciences participated in the research. A semi-structured interview was conducted by the researchers based on 10 open-ended questions about foreign language anxiety.

Results. Although the perceptions of students' own English language competence were found to be an important source of anxiety for the interviewed students, most of the respondents perceive the necessity of trying to cope with stress and anxiety themselves. In addition, instructors appeared to be creating the feeling of relaxation rather than being the anxiety-provoking ones in the classroom.

Conclusion. Awareness of the fact that FLA really exists and appears to be an obstacle for students' academic achievement needs to be acknowledged. To address this issue, collaboration rather than competition must be implemented as a tool in classes for further advancement in learning. Therefore, these measures might help to reinforce self-esteem and achieve better results in the foreign language classroom and, thus, in the overall goal of studies in the student learning process.
\end{abstract}

Keywords: language acquisition, foreign language anxiety, higher education.

\section{INTRODUCTION}

$\mathrm{R}$ ecent research of foreign language anxiety found that anxiety as a basic human emotion originates from the learner's own self (Scovel, 1991). A number of studies on anxiety report on the significance of it as an issue continuing to exist in the university foreign language classroom. A feeling of nervousness associated with foreign language learning is termed as foreign language anxiety (FLA). The construct of FLA was first investigated by Horwitz, Horwitz \& Cope (1986). Horwitz, Horwitz, \& Cope (1991) views FLA as a distinct complex of self-perceptions, beliefs, feelings, and behaviours related to classroom language learning arising from the uniqueness of the language learning process. MacIntyre (1998) conceives of LA as the worry and negative emotional reaction aroused when learning or using a second language. Recent research of foreign language anxiety has been focused on quantitative studies (Ghadirzadeh, Hashtroudi \& Shokri, 2012) although a lack of information still exists about the phenomenon of FLA, its causes and effects on the foreign language acquisition and overall educational outcome of 
students. Nevertheless, some researchers applied different methods of research, i.e. Tanveer (2007) focused on the qualitative format of the research and used semi-structured interviews and focus group analysis while examining FLA in the higher education context. In addition, there was research performed by Tóth (2011) and Riasati (2011) who aimed at deeper insight into the element of FLA by analyzing students' own perceptions on the reasons of FLA existing in the classroom. Consequently, an in-depth approach to the construct of language anxiety is needed in order to gain better understanding of FLA and the ways to eliminate or reduce it should be sought. Therefore, research aim was to investigate the self-perceptions of students, engaged in sports, about foreign language anxiety in the classroom context in relation to its effect on foreign language acquisition and overall academic achievement as well as to develop strategies how to alleviate foreign language anxiety in the university foreign language classroom.

\section{METHODS}

As the research aimed at the examination of FLA through the students' personal experiences, the qualitative approach of research was adopted in this study, as it allowed us to gain a deeper insight into the students' own perceptions about FLA as an obstacle for the progress of their academic development. Twenty subjects, engaged in sports or choosing sports activities during their leisure time, involved in the study programs as Sports Coaching at the Lithuanian Sports University (LSU) and Medicine at the Lithuanian University of Health Sciences (LSMU) participated in the research. They can be regarded as typical EFL learners with different FL level, learning the target language almost exclusively in a monolingual classroom, typically from non-native teachers of English, with limited or wider opportunities to use the language for communication outside the classroom. A semi-structured interview was conducted by the researchers based on 10 open-ended questions about anxiety (adapted from Tanveer (2007)).The procedure involved the pilot interviews to gather initial information. The instruction contained the theoretical background about the research as well as a written consent form was signed by the participants, that is, they voluntarily participated in the research knowing that their reflections would be anonymous and their identity would be kept in secret. Secondly, a questionnaire asking about general background of students (age, gender, study program and English language level) was asked to fill in (Table).

Furthermore, 10 questions aboutFLA were asked during one-to-one interviews with the respondents so that to gain more explicit aspects, emotions and reflections about the phenomenon of anxiety. Each interview lasted 15-20 minutes. The received data were collected and analyzed using the coding system, breaking the material into comprehensible themes or subthemes and performing the reduction of the collected information.

\section{RESULTS}

The in-depth interviews revealed that the students' self-perceptions of foreign language may be analysed under headings as emotions and feelings of the students, psycho-physiological symptoms, FLA in classroom and real life, the role of mistakes, the role of a teacher, respondents' selfperceptions of their own language competence as well as strategies for alleviating FLA.

Positive/negative feelings and emotions. Most of students noted their satisfaction while learning English, so their experience appeared to be rather positive than negative one, the language provided the opportunity to know other cultures; they have built good knowledge of English, etc. Only one interviewee reported that his experience was both positive and negative.This positive attitude may be based on the perception of English being not a very difficult language to learn. However, there were situations at English classes when students felt discomfort and stressed.The most important reasons they offered as an explanation for their feelings of insecurity and discomfort was the fact

Table. Respondents' background profiles

\begin{tabular}{|c|c|c|c|c|c|}
\hline University & Number of participants & Age & Gender $(\mathbf{F} / \mathbf{M})$ & Years of studying EFL & English language level \\
\hline LSU* $^{*}$ & 10 & $19-21$ & $4 / 6$ & $8-14$ & A2, B1, B2/C1 \\
\hline LSMU* $^{*}$ & 10 & $19-21$ & $8 / 2$ & Av. 10 & B2/C1 \\
\hline
\end{tabular}

Note.* LSU - Lithuanian Sports University, LSMU - Lithuanian University of Health Sciences. 
that they dreaded being called upon and having to speak up in class, especially being unprepared for that. Also some of them get stressed when they had to give quick answers to the questions, when they were unable to express themselves or when the structure of the sentence was incomprehensible.

Psycho-physiological symptoms. The participants' English-related anxiety manifested itself in the form of rather unpleasant psychophysiological symptoms. Different forms of fear were sometimes accompanied by physiological changes like blushing, getting confused, forgetting the words, and starting mumbling as the following excerpts show: "My voice starts to shake and my palms get wet", "I forget what I was saying, I forget the words and use more simple ones". As the research showed most of the respondents try to cope with stress and anxiety: "I try to calm down and stress tends to disappear"; "I feel confused, I blush, but then I try to concentrate and solve all my problems, like voice trembling".

Language classes vs. real-life situations. Firstly, most respondents reported that the most of language experience was gained in certain reallife situations (sports camps, competitions) but a few responders marked insufficiency of their FL experience and knowledge due to poor studying at school or university. They also noted that they could clearly express themselves in a foreign language despite making mistakes. Some of the respondents marked that it was easier to communicate with foreigners or close friends in a foreign language than participate in classes at the university.

Secondly, the main causes of anxiety in language learning in a classroom setting is a perceived standard, the opinion of other students and the teacher, and fear of the effect of their mistakes. All interviewees were of the opinion that speaking English in the classroom was different and more anxiety provoking than communicating with their friends and family members or even native speakers outside the classroom: "I don't feel anxious when I speak to my friends or family members"; "When I am abroad and I speak to people I don't know I feel not stressed"; "People don't notice small mistakes and the most important thing is to be understood".

As shown by interviewees' comments, they see their English classes as the place where they constantly have to prove their high standard of English to their peers and the teacher, which causes FLA: "Everyone speaks fluently in the classroom you must know and speak English well"; "The opinion of other students that you have to speak English fluently disturbs me most".

Mistakes and students' self-perception of L2 competence. The most common linguistic difficulties reported by the students were the lack of vocabulary, the complex nature of English grammar, pronunciation and accent.

The respondents pointed that the lack of English vocabulary, especially not knowing the professional terminology, led them to disturbance while learning and speaking the language (" $<\ldots$. not knowing different terminology in English"). Some of the students indicated that the English language was not difficult but lack of words made them feel confused (" $<\ldots>$ but unknown words make understanding more difficult"). The respondents encountered challenges in memorizing some words or problems in understanding the speaker as well ("I don't understand what people say to me"; "<...> not difficult but unknown words make understanding more difficult"; “<..> it's difficult because of unclear pronunciation of other people"). Therefore, the problem with vocabulary appeared to be twofold: insufficiency of enough words and retrieval of the vocabulary.

Thirdly, the issue of grammar anxiety has been found to be an important factor impacting the use of FL. Some students (possessing lower FL level) revealed that lack of grammatical knowledge such as not knowing grammar rules and the complexity of the tense system embarrassed them markedly when speaking English: " $<\ldots>$ when you need to change tenses", " $<\ldots>$ the more I learn, the more I make grammar mistakes", "difficult as what tense to use" <..>; " <.. > most problems are grammar problems". Such examples witness that the respondents feel anxiety because they lack grammatical knowledge and this results in problems in making sentences correctly. Most respondents comprehended that the insufficiency of grammar knowledge and English words led to their inability to express themselves in a foreign language.

Moreover, pronunciation was accounted to be a big cause of FLA as well. Most students reported challenges in the comprehension stage, for instance, they pointed that they sometimes were unable to understand foreign people because of their accent (" $<\ldots>$ it's difficult because of unclear pronunciation of other people"). In addition, the respondents also struggled to not making mistakes when pronouncing words in class ("I feel fear of 
using not correct word or mispronounce it"). Typically, students make a conscious effort to speak English correctly, trying hard to avoid mistakes in the classroom setting. This sometimes makes them tense and uncomfortable.

One of the major concerns shared unanimously by the participants of the research in the classroom was their fear of speaking the language inaccurately. Only one student noted that she was afraid of making mistakes because of poor evaluation. A number of students reported fear and anxiety about their peers' reaction (" $<\ldots$..> speaking in front of audience"; “ $<\ldots>$ when you speak to people who know English well"; " < ..> situations where unknown people would laugh at your mistakes $<\ldots>$ ";" $<\ldots>$ when you speak and somebody listens to you <...> "," bullying "). Thus, the reported answers prove that the competitiveness exists among students and they also receive negative or humiliating reactions from their peers. Moreover, being corrected by the teacher or even other students seems to be one more source for FLA ("I am afraid of making mistakes as teachers or other students usually try to correct me"). However, one interviewee said that in his opinion making mistakes was normal.

Furthermore, according to the received data, fear of exams, tests or making mistakes result in negative educational outcomes for most students. The respondents reflected they were test or exam anxious ("I am anxious when my knowledge is evaluated"; "<...> situations when speaking or writing is evaluated").

What is more, making mistakes, always reported as an obstacle in studying a foreign language, was perceived as a natural step towards development by some of the respondents ("I am afraid a little, but you must try not to make mistakes and learn from them"; "I am not afraid of mistakes and try not to repeat them"; "I am afraid of reactions of unknown people especially when you make mistakes"; "I am not afraid of mistakes or other people reactions"; "I am learning not to be afraid").

Moreover, the respondents' perception of their communication skills has been reported to be anxiety-breeding. "Speaking is very difficult as I can understand many things but I cannot express my thoughts", - said one of the respondents. Most of the students believed that communication apprehension hindered their learning process and demotivated them ("Speaking on the spot, without preparation, is difficult"; "Public speaking is difficult"; "Learning by heart disturbs me").
Besides the perceptions concerning the language-learning situation (required standard, teachers' expectations, peers' proficiency), perceptions of their own English language competence were found to be another important source of anxiety for the interviewed students. Eight of them expressed dissatisfaction with their L2 proficiency, particularly their speaking skills.

These findings suggest that facing their limitations in English and failure to live up to their own personal expectations and the expectations of the surrounding environment was a major source of anxiety for the interviewed students.

The teacher. The role of a teacher appeared to be significant in maintaining low level of language anxiety. The respondents reported that the teacher played a neutral role or decreased the level of anxiety in most cases (" $<\ldots>$ does not cause anxiety $<\ldots>$ "; " < . . > plays neutral role $<\ldots$..> "; " < . . $>$ teacher reacts calm and controls the situation"; " <..> anxiety decreases when you talk only to teacher"; " $<\ldots>$ teacher decreases the level of my anxiety, helps and makes individual speaking tasks"; “ $<\ldots>$ teacher decreases the level of anxiety"). The teacher, in their opinion, plays the biggest role of all. They think that it would be much worse without the teacher's assistance. The teacher is the person who encourages or suppresses students' confidence. So it is the teacher's role to create the atmosphere of comfort and fearlessness. One of the students said that teachers at school created the feeling of anxiety, but at the university they created the feeling of relaxation. As the teacher encouraged them to speak more and did not laugh at their mistakes this made the atmosphere at English university classes relaxing ("Every teacher of English was nice and not very strict, and that helped me"; "If the teacher is good and kind the lessons and the language itself become more interesting").

How to reduce FLA in the learners? In line with the students' responses, the perception of the need for further individual development in language learning was identified by the respondents themselves. The interviewees showed their enthusiasm in eliminating mistakes, increasing vocabulary and realization of their tribute in language learning as well (" $<\ldots>$...relax and should have studied more at school $<$...> "; “ < ...> eliminate shortage of knowledge resulting from school activities"; " < ...> try to learn harder <...> "; “ $<\ldots>$ not to pay attention to others' reactions but to focus on your own mistakes"). 


\section{Role of a teacher}

Creates an encouraging and relaxing atmosphere in class; provides reassurance and help;avoids frequent evaluation; gives tasks where students feel successful

Expected successful teaching process; achievement of teaching aims and objectives; satisfaction and self-realization

\section{Role of a student}

r.

Realizes that mistakes are a part of a learning process; takes responsibility for preparation and deepens knowledge in and out classroom; takes measures to decrease stress and anxiety individually

Positive outlook on learning FL; increased self-esteem, inner motivation, decreased anxiety, increased academic achievement

Figure. Strategies for alleviating FLA as recommended by the respondents for successful university learning

The opinions of the interviewed students on how to reduce FLA can be divided into two groups: a) the role of the teacher and b) the role of students themselves (Figure).

In order to reduce language anxiety in learners, students should be encouraged to speak more and especially encouraged speaking on the spot when students are unprepared for the task.

Teachers should not be strict; they should let students discuss not only professional topics but also about various life situations. Then English classes could become fun and without stress, not just like other classes. Teachers should also take into consideration that students may have different level of proficiency in English and not judge them equally ("Teachers should change their attitude that you already know this because you know the language, but not all of us have the same level of English").

Teachers should make students believe that making mistakes is a part of the learning process. In the interviewed students' opinion big responsibility in learning a foreign language is on the students' shoulders. To give some comments: "I have to speak as much as possible and learn more new words"; "I have to try speak more slowly"; "I don't have to think what others may think about you and try thinking in English not in Lithuanian".

In summary, the most important issues discussed above lead to demotivation and lowering of selfesteem as the respondents recognized themselves ("Knowing that you won't be able to do some tasks"; "I usually get confused and begin speaking in my native language"; " $<$...> when you still don't know things you had to learn at school”; " $<\ldots$.. not good preparation, little practice"; " <... when I pay too much attention to my unsuccessful speech"; "<... poor psychological attitude"). Perceptions of their own English language competence were found to be an important source of anxiety for the interviewed students. Nevertheless, the answers of the respondents suggested a rather positive attitude of anxious learners towards learning English. Most of the respondents perceived the necessity of trying to cope with stress and anxiety themselves. Moreover, the study found that the advanced-level students still experience moderate levels of FLA in their university English classes (fear of public speaking, fear of being misunderstood, fear of the effect of the mistakes made, fear of being laughed at by their peers, fear of looking stupid, etc.) . That is in line with the studies by Toth (2011) who found that more proficient students were more comprehensible about their limitations and mistakes in learning languages.

In addition, the study found that speaking English in the classroom was different and more anxiety provoking than communicating with their friends and family members outside the classroom.

What is more, a friendly, encouraging role of teachers appeared to be crucial in the university classroom setting. As the findings suggested, teachers should take into consideration that students may have different level of proficiency.

The remediation of FLA anxiety should encompass the corporate efforts of both students and teachers resulting in the reduction of the existing FLA and, thus, facilitation the process of foreign language learning. 


\section{DISCUSSION}

The in-depth interviews revealed that foreign language anxiety continues to persistently exist due to: (1) insecurity and discomfort in class, (2) linguistic difficulties, such as lack of sufficient vocabulary, a poor command of grammar rules and pronunciation difficulties, cognitive challenges: fear of failure (failure in communication, failing in exams, making mistakes, failing in front of others), lack of self-esteem, (3) the role of the teacher, and (4) other reasons (competitiveness, lack of preparation).

What emerged from students' accounts of their current language learning experience is their positive attitude towards learning English. However, they felt insecure and uncomfortable in class sometimes. According to Hashemi (2011), the students usually blame strict class environment as being a potential threat to their success in class as well as meeting high standards of university education. Insecurity and discomfort are feelings accompanying FLA phenomenon. As outlined by Kayaoglu and Saglamel (2013), this phenomenon is usually followed by visible physical changes commonly re-occurring during lectures. Most of the learners reported that they had experienced psychological and physical changes, like trembling of hands, rapid heart beating, bad sleep, and blush. Some of them believe that even their behaviour changes when they suddenly start laughing at the lesson, they feel frightened, worried, excited, lost, disorientated, not self-confident and shameful.

Moreover, the most common linguistic difficulties reported by the students were the lack of vocabulary, the complex nature of English grammar, pronunciation and accent.

Most respondents comprehended that the insufficiency of English words leads to their inability to express themselves in a foreign language. As in the research by Toth (2011) who found that there was a gap between native and foreign languages the respondents also encountered challenges in translating because of the different structure of foreign and native languages.

The issue of grammar anxiety has been found to be an important factor impacting the use of FL. Some students revealed that lack of grammatical knowledge such as not knowing grammar rules and the complexity of the tense system embarrassed them markedly when speaking English.

Besides, pronunciation appeared to be a big cause of FLA as well. Most students reported challenges at the comprehension stage, for instance, they pointed that they sometimes were unable to understand foreign people because of their British accent. In addition, the respondents also struggled to not make mistakes when pronouncing words in class. This finding is in agreement with Riasati's (2011) study on FLA where the respondents also pointed that the speed of speech, intonation patterns and listening activities is becoming a problem for most students in FLA learning.

In line with the responses, cognitive challenges included failing in front of others, competitiveness, fear of exams, tests, making mistakes, evaluation, failure in communication and lack of self-esteem.

Firstly, the collected data revealed that students feel fear to fail especially in front of their peers. A number of students reported fear and anxiety about their peers' reaction. Thus, the reported answers prove that competitiveness exists among students and they also receive negative or humiliating reactions from their friends.

It is interesting to note that some respondents proved to be self-conscious and pointed that they did not pay attention to other students' reaction. Those students appeared to possess a higher level of English language (B2/C1). That is in line with the studies by Toth (2011) who found that more proficient students were more comprehensible about their limitations and mistakes in learning languages. Furthermore, according to the received data, fear of exams, tests or making mistakes result in negative educational outcomes for most students as well as making mistakes or receiving low evaluation were considered to be the major obstacles in studying a foreign language. Conversely, some subjects of the research reported that they were not afraid of making mistakes and considered that making mistakes is normal in the learning process.

Failure in communication has been reported to be anxiety-breeding by the respondents. The fear of communicating orally and public speaking anxiety has long been accepted as psychological phenomena. Hashemi (2001) noted that fear of giving a speech exceeded even such phobias as fear of snakes, elevators, and heights. Some participants of the present research noted that just knowing that they will have to speak in front of other people puzzles them and makes them nervous; especially when they have to speak on the spot, without preparation and lack of time for preparation has been reported to be one of additional factors causing learners' anxiety. Other students report that public speaking 
is difficult as they cannot understand many things to express their thoughts. These findings are congruent with those of Riasati (2011) who argued that if students are not prepared enough for the activity, they feel anxious, which affects their performance. Thus, communication apprehension hindered their learning process and demotivated them.

One more source of foreign language anxiety is a teacher. Teacher-generated anxiety was documented in much earlier research done by another researcher, such as Price (1991). They reported significant teacher-generated anxiety and examined teacher-learner interactions. Williams \& Andrade (2008) argued that teachers shoulder a greater responsibility nowadays. According to Kayaoglu and Saglamel (2013), the center of gravity in FL teaching/learning has been shifted because of the growing student autonomy. Now teaching has undoubtedly become student-centered. However, learners still attach a significant role to teachers and they look at the teacher as the key tool of success or failure. At the same time they fail to notice that the teacher is only one factor in all learning process.

The present research revealed quite positive attitude to the teacher's role in causing language learning anxiety. Some participants of the research noted that teachers in their language learning classes are good and very understanding. Teachers either take a neutral position or minimize tension and anxiety, thus, encouraging them to speak in English.

However, some of the research subjects are embarrassed by the teacher correcting their mistakes or even feel some pressure from teachers when they want too much from the person. The teacher's interference disturbs these learners: they can lose their thought and are not able to concentrate on the topic.

The participants of the present research believe that there are ways that could help to relieve stress and anxiety in language learning. This could be done both by teachers and students. The teachers can make a stress-free language learning environment in which students can learn the material confidently. With regard to factors that could reduce learning anxiety the participants of the present research mentioned more written assignments instead of oral, enough time for preparation, the same level of students' proficiency in the group, speaking to their peers but not to the teacher, no evaluation, more focus on the terminology in the field; etc.

Finally, the respondents of the study are of the opinion that students themselves can help relieve their anxiety so as to be more successful in foreign language learning. Students have to learn more independently and step aside their comfort zone. They have to prepare better for the lesson, attempt to develop their speaking skills, learn more words, watch films, TV in English and communicate with foreign people. Some of them also mention that the most important thing is to be self-confident and not to be afraid of making mistakes, thus increase their self-esteem and communication experience.

Consequently, the findings of the research are congruous with the opinion that only corporate efforts of all of them together can reduce the existing FLA and, thus, facilitate the process of foreign language learning.

Recommendations for further research. As foreign language anxiety gradually diminishes with increasing proficiency and experience, further research should focus on the comparison of low and higher level students' FLA in-class experiences and out-of-class settings (real life, communicating with professionals in the fiels abroad, self-study in foreign language, following sports career or pursuing active leisure activities). Moreover, the role of an instructor may be significant for further research as well. Thus, focus group analysis for the teachers' perceptions of students' FLA in class may be beneficial for the in-depth study of FLA in university education.

\section{CONCLUSIONS}

1. Awareness of the fact that FLA really exists and appears to be an obstacle for students' academic achievement needs to be acknowledged.

2. The analysis of a personality as well as eliminating possible hindrances or obstacles such as cognitive and linguistic problems while learning FLA are considered to be vital for progress.

3. Not only pedagogical or psychological methods are needed, but also collaboration rather than competition must be implemented as a tool in classes for further advancement in learning.

4. These measures might help to reinforce selfesteem and promote intrinsic motivation of students paying more attention to the building and reinforcing their personalities' development to achieve better results in the foreign language classroom and, thus, in the overall goal of studies in the student learning process leading to a successful career in future. 


\section{REFERENCES}

Ghadirzadeh, R., Hashtroudi, F. P., \& Shokri, O. (2012). Demotivating factors for English language learning among university students. Journal of Social Sciences, 8(2), 189-195. Retrieved from http://thescipub.com/ PDF/jssp.2012.189.195.pdf

Hashemi, M. (2011). Language stress and anxiety among the English language learners. Procedia-Social and Behavioral Sciences, 30, 1811-1816. doi: 10.1016/j. sbspro.2011.10.349

Horwitz, E. K., Horwitz, M. B. \& Cope, J. (1986). Foreign language classroom anxiety. The Modern Language Journal, 70(2), 125-132. Retrieved from http://www.jstor.org/stable/327317

Horwitz, M. B., Horwitz, E. K., \& Cope, J. (1991). Foreign language classroom anxiety. In E. K. Horwitz, \& D. J. Young (Eds.), Language anxiety: From theory and research to classroom implications (pp.27-39). Englewood Cliffs, New Jersey: Prentice Hall.

Kayaoglu, M. N., \& Saglamel, H. (2013). Students' perceptions of language anxiety in speaking classes. Journal of History Culture and Art Research, 2(2), 142 160. doi: 10.7596/taksad.v2i2.245

MacIntyre, P. D. (1998). Language anxiety: A review of the research for language teachers. In D. J. Young (Ed.), Affect in foreign language and second language learning (pp. 24-45). Boston: McGraw-Hill.

Price, M. L. (1991). The subjective experience of foreign language anxiety: Interviews with highly anxious students. In E. K. Horwitz \& D. J. Young (Eds.), Language anxiety: From theory and research to classroom implications (pp.101-108). Englewoods Cliffs, NJ: Prentice -Hall.

Riasati, M. J. (2011). Language learning anxiety from EFL learners' perspective. Middle-East Journal of Scientific Research 7(6), 907-914. Retrieved from https://www.idosi.org/mejsr/mejsr7 (6)11/13.pdf

Scovel, T. (1991). The Effect of affect on foreign language learning: A review of the anxiety research. In E. K. Horwitz \& D. J. Young (Eds.) Language anxiety: From theory and research to classroom implications (pp.15-24). Englewood Cliffs, NJ: Prentice Hall.

Tanveer, M. (2007). Investigation of the factors that cause language anxiety for ESL/EFL learners in learning speaking skills and the influence it casts on communication in the target language (Dissertation of Master studies). University of Glasgow: Scotland.

Tóth, Z. (2011). Foreign language anxiety and advanced EFL learners: An interview study. Working Papers in Language Pedagogy, 5, 39-57. Retrieved from http:// langped.elte.hu/WoPaLParticles/W5Toth.pdf

Williams, K. E., \& Andrade, M. R. (2008). Foreign language learning anxiety in Japanese EFL university classes: Causes, coping, and locus of control. Electronic Journal of Foreign Language Teaching, 5(2), 181191. Retrieved from http://e-flt.nus.edu.sg/v5n22008/ williams.pdf 